\title{
Acute effects of static stretching on flexibility: A comparative study among students to identify the best timing to improve flexibility
}

\author{
Ayumi Shukuya ${ }^{1}$, Asako Zempo-Miyaki ${ }^{2 *}$, Tomohiro Ogai $^{2}$ and Takeshi Otsuki ${ }^{2}$ \\ 1流通経済大学スポーツ健康科学研究科, =301-8555 茨城県龍ケ崎市 120 (Ryutsu Keizai University, Graduate School of \\ Health \& Sport Sciences, 120 Ryugasaki, Ibaraki 301-8555, Japan) \\ ${ }^{2}$ 流通経済大学スポーツ健康科学部, 『301-8555 茨城県龍ケ崎市 120 (Ryutsu Keizai University, Faculty of Health \& Sport \\ Sciences, 120 Ryugasaki, Ibaraki 301-8555, Japan)
}

Received: March 23, 2021 / Accepted: July 14, 2021

\begin{abstract}
Flexibility is an important factor of physical fitness to prevent sports injuries. However, the best timing to improve flexibility during the growth and development period in children has been unclear. To compare the acute effects of static stretching on flexibility between school-grade children in the growth and development period, we measured the hip joint flexion range of motion (RoM) by using straight leg raising (SLR) before and after static stretching (6 exercises, 15 seconds, 2 sets) in 50 young male children aged 7 to 13 years (the second grade of elementary school to the first grade of junior high school). The RoM in SLR significantly increased after stretching versus that before stretching in all subjects. This positive improvement of RoM was statistically significant among all grade levels. Notably, the change rate in RoM after stretching was significantly greater in the fourth grade of elementary school than in the other grades. The rate of height increase during the past year was lower in students from the fourth grade than in students from the second grade of elementary and the first grade of junior high school. These results suggest that flexibility training is more effective during the slowdown period of growth and development in young male children.
\end{abstract}

Jpn J Phys Fitness Sports Med, 70(5): 307-314 (2021)

Keywords : flexibility, growth and development, static stretching, RoM

\section{緒言}

小中学生約 5 万 4 千人に扔ける運動器健診の結果をま とめた近年の報告は, 脊柱・下肢変形等の推定被患率は $10 \%$ 弱，機能不全者（しゃがみ込み動作の不能）の割 合は約 $7 \%$ であったとしている ${ }^{1)}$. 帖佐 ${ }^{1)}$ は，前者は運 動多過に, 後者は運動不足に由来すると指摘し, 運動習 慣の二極化によりロコモティブ・シンドロームが増加す ることを懸念している，この懸念を解消するうえでは柔 軟性の改善が不可欠だと考えられる。例えば，ジュニア 時代から運動多過が継続するとスポーツ障害のリスクが 高まるが，過去 1 年以内に肩痛で全力投球できない時期 がなかった大学女子ソフトボール選手では，そのような 時期があった選手よりも肩関節の可動域（range of motion: RoM）が大きかったと報告されている2).また，運

*Correspondence: zempo@rku.ac.jp
動不足は動作不能のリスクを高めるが, 踵接地でしゃが むことのできる子どもはできない子どもより長座体前屈 の成績に優れることも報告されている ${ }^{3)}$. さらに，運動 習慣の二極化に伴うスポーツ障害および動作不能のリス ク管理に止まらず，新体操拈よびフィギュアスケート等 の審美系スポーツをはじめとするアスリートのパフォー マンスを高めるうえでも柔軟性は重要な因子である ${ }^{4}$. これらのことから，あらゆる児童・生徒の柔軟性を向上 させる積極的な取り組みが，学校現場および地域総合型 スポーツクラブ等には必要だと考えられる。

ストレッチングは柔軟性を高めるトレーニング手段で ある、特に静的ストレッチングは動的ストレッチングよ りも RoMの改善効果が大きいとされて㧍り ${ }^{5)}$, 成人にお けるメ夕解析でもその効果が検証されている ${ }^{6)}$ ．未成年 に扔けるストレッチングの効果も, 小学校の授業7) およ び思春期前の体操選手 ${ }^{8)}$ に打ける介入研究で明らかにさ れている。ただし，柔軟性トレーニングの至適年齢につ 
いては十分に研究が行われているとは言えない. 例えば, トレーニング開始の至適年齢を論じた大澤の総説 ${ }^{99}$ は, 文部科学省による体力テストのデー夕を基に柔軟性の発 達が最大になる年齢を示すに止まっている，7～11歳の 間に柔軟性を向上させることが効果的だと主張するオル ター ${ }^{10)} も ， そ の$ 根拠は年齢と柔軟性との関係を検討した 横断的研究 ${ }^{11)}$ である, 我々の知る範囲では, 実際に様々 な年齢の子どもに柔軟性を高めるトレーニングを行わせ た研究として, 斎藤ら ${ }^{12)}$ の研究がある。そこでは, 体 操教室（週 2 回，2 力月間）による柔軟性の改善度合い が年齢（4１0歳）により異なる可能性が示されたが, 年齢によって男女比が異なるなど, 更なる検討が必要で ある。もし，柔軟性トレーニングの至適年齢が明らかに なり，その年齢で集中的にストレッチングに取り組んで 柔軟性を高めることができれば，当該年齢はもとより成 人後も含めた長期的な障害予防および競技パフォーマン スの向上等に資するかもしれない.

学童期から思春期にかけては, 筋肉よりも骨の伸長が 速いために柔軟性が低下寸ると考えられている ${ }^{10)}$. また, 小学 6 年生男子の股関節 RoM と体重抢よびbody mass index（BMI）との間に負の相関関係が認められたこと から ${ }^{13)}$, 筋量の増大が柔軟性を低下させる可能性も指摘 されている。 これらの研究からは, 成長が著しい時期は 柔軟性が低下するだけでなく柔軟性のトレーニング効果 も低い可能性が考元られる。 そこで本研究では，思春期 の急成長期 (adolescent growth spurt: AGS) ではス卜 レッチングの効果は小さく，その逆に，AGSを控え身 体の成長が一時的に停滞する時期ではストレッチングの 効果が大きいという仮説を設定した。この仮説を検証す るために, 本研究では, ストレッチングによる股関節屈 曲 RoMの一過性の改善効果を学童期の学年間で比較す ることとした。先行研究 ${ }^{14-22)}$ からは, 男子では中学 1 年がAGSに, 小学 4 年が成長停滞期に, 小学 2 年生が 成長停滞期を控え成長速度が上昇する時期 (mid-growth spurt: MGS）に概ね該当すると考元られる，そこで，本 研究の対象者は小学 2 年生〜中学 1 年生男子とし, ス卜 レッチングの前後で下肢伸展挙上 (straight leg raising: SLR）により股関節屈曲RoMを評価して, その効果を学 年間で比較した。学校体育の授業等, 体育・スポーツは 学年単位で実施されることが多い，至適年齢に該当する 学年では準備・整理運動でストレッチングにより多くの 時間をかけるなど，得られた知見を現場で活用しやすい ように, 本研究では対象者を年齢ではなく学年で群分け した，また，男女で身長の発育速度 ${ }^{22}$, 各体力要素の発 達パターン ${ }^{9)}$, 下肢の柔軟性 ${ }^{13)}$ が異なるうえに, 女子の 柔軟性は月経周期の影響を受ける可能性がある ${ }^{23)}$. そこ で, 本研究では男子を対象にした。

\section{方法}

対象者 本研究の対象者は, 小学校 2 年生から中学校 1 年生の男子 60 名である。ただし、デー夕久損がある者を 除外し，50名を分析対象にした。

本研究はヘルシンキ宣言に従い, 流通経済大学入ポー ツ健康科学研究科修士論文研究倫理審查委員会の承認を 得て実施した (平成 27 年第 1 号). 実験を開始する前に, 対象者の保護責任者に書面および口頭で実験内容等を説 明し，書面による同意を得た上で，対象者に研究の目的 と実験内容について口頭で説明し, 実験参加に対する同 意を得た。

SLR SLRによる股関節屈曲 RoM 測定は, ストレッチン グの前後において, 我々の先行研究 ${ }^{24)}$ に従って実施した. 対象者は, $0 \sim 180^{\circ}$ まで $5^{\circ}$ 刻みの分度器を模した半円 の円心の前に大転子が位置するように仰臥位になり，右 脚のSLRによるRoMの測定を行った，RoMは 3 秒間静 止できる最大角度とし，5刻みで值を読みとった，対 象者には, 膝を曲げずに, 股関節の最大屈曲位を 3 秒以 上保持するように指示した。その際には, 軸脚（左脚） の代償動作（膝関節の屈曲, 臂部が浮くなど）が生じな いように，また，息こらえをしないように注意した，測 定は補助者と検者の 2 人 1 組で行い, 補助者は代償動作 が起こらないよう対象者を補助した，検者は膝の完全伸 展位を保てる範囲で対象者の踵が越えた角度を読み取っ た，検者は全ての測定で著者 SAが務め，ストレッチン グ前後で補助者を替えずにRoMを測定している，RoM 測定は 2 回ずつ行い，最高値を分析に用いた，連続した 2 日間の同時刻にRoM を測定した際の検者内変動係数 は3.7 $3.0 \%$ であった ${ }^{24)}$.なお，測定およびストレッチ ングは体育の授業がない日の昼休みに, 準備運動（屈伸, 伸脚, アキレス腱伸ばし, 前屈, 後屈, 手首㧍よび足首回 し；各10秒間）を行ったうえで実施した。

ストレッチング 先行研究 ${ }^{25)}$ を参考に, 能動的な下半 身の静的ストレッチングを 6 種目，15秒間， 2 セット 実施した。ストレッチングは著者SAが見本を示し，複 数の研究補助者が個別に指導や補助にあたる体制で実施 した，本研究に扔けるストレッチングの構成は, 股関 節屈曲・内旋による臀筋のストレッチング 1 種目（Fig. $1 \mathrm{~A})$ ，股関節屈曲によるハムストリングスのストレッチ ング 3 種目 (Fig. 1B-D), 足関節背屈による下腿三頭筋 のストレッチング1種目 (Fig. 1E)，股関節伸展による 腸腰筋のストレッチング 1 種目 (Fig. 1F) とした。 スト レッチングは息を止めたり反動をつけたりしないで行う ように，また，種目ごとにストレッチされる部位を意識 して行うように指示した。 
A

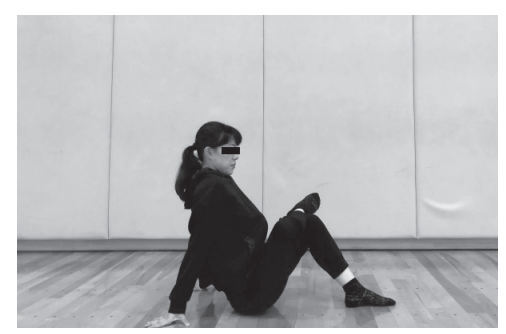

$\mathrm{C}$

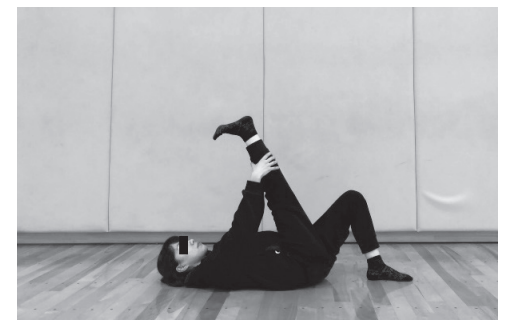

E

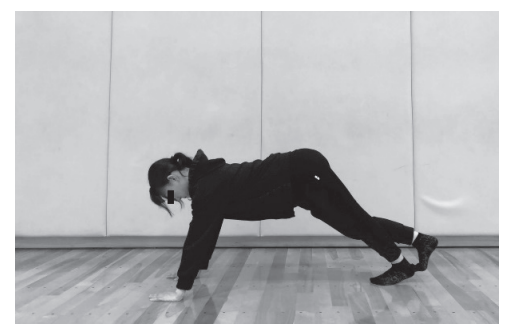

B

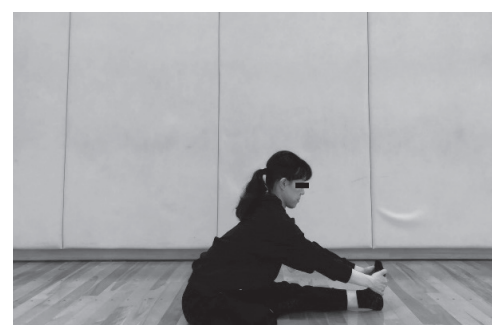

D

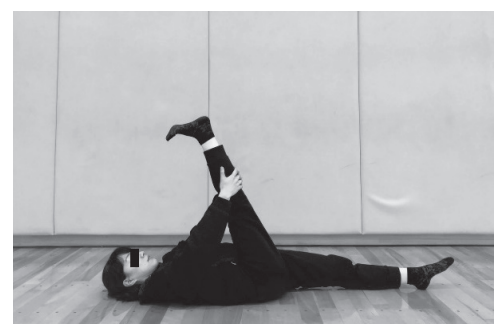

F

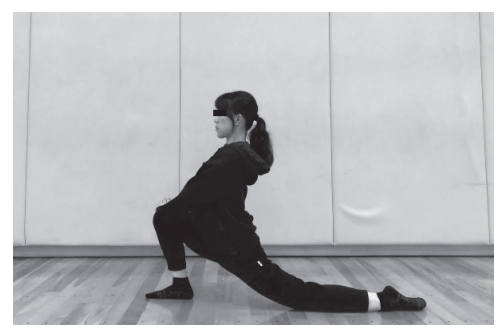

Fig. 1 Examples for static stretching.

身長, 体重, ローレル指数 対象者が所属する学校から, 学校長の了解を得て, 定期形態測定における身長および 体重のデー夕提供を受けた。デー夕提供の対象は, 実験 実施時の直近および 1 年前の定期形態測定である。ロー レル指数はこれらの值を用いて算定した.

統計分析 全対象者におけるストレッチング前後の股関 節屈曲 RoM の比較は対応のある $t$ 検定によって行った. 学年により群分けした検討では, 繰り返しのある二元配 置分散分析により主効果および交互作用（RoMでは学年 ×ストレッチング前・後, 身長・体重・ローレル指数で は学年 $\times$ 測定時・ 1 年前）の有無を確認した。事後検定 にはボンフェローニ法を用いた. また, 効果量 (Cohen’s d) を算定し，ストレッチングの前と後，実験時とその 1 年 前との比較を行った. 先行研究 ${ }^{26)}$ に従い, 効果量 $>0.2$ は 効果小, $>0.5$ は効果中, $>0.8$ は効果大と解釈した. さらに, ストレッチングによるRoM の変化率, 過去 1 年間にお ける身長, 体重, ローレル指数の変化率の学年間比較を,
一元配置分散分析およびダネット法により行った。

統計分析にはSPSS ver. 17 を用いた。有意水準は $P<0.05$ に設定し， $0.05 \leqq P<0.1$ を有意に近い水準とした.

\section{結果}

小学 2 年生から中学 1 年生までの全対象者 50 名にお いて, 股関節屈曲RoM はストレッチングの実施前に比 べて実施後に向上した（64 $\pm 6^{\circ}$ vs. $73 \pm 8^{\circ} ; P<0.01, C O$ hen's $d=1.1$ ). 学年で群分けした検討では, 二元配置の 分散分析において, ストレッチング $(P<0.001)$ および 学年 $(P=0.006)$ の主効果は有意であり, これらの交互 作用 $(P=0.09)$ は有意に近い水準であった。事後検定 および効果量による検定では, ストレッチングによる RoM の改善は全学年で有意 $(P<0.05)$ かつ効果量は中 等度以上 (Cohen's d>0.5) であった。ただし, 効果量は 小学 4 年生 $(3.13)$ が他学年 $(0.66 \sim 1.49)$ に比べて突出 して大きかった（Table 1). また，ストレッチングによ る RoM の変化率は, 小学 4 年生 $(26.0 \pm 11.6 \%)$ で他の 
全学年（6.2 $\pm 5.5 ~ 15.8 \pm 9.6 \%)$ よりも有意に大きかった (Fig. 2).

身長扮よび体重に，学年㧍よび実験実施時・ 1 年前の 主効果が認められ（全て $P<0.001$, Table 2$)$, 全学年で 1 年前に比べて実験実施時に高值を示した。これらに有意 の交互作用は認められなかったが $(P=0.96, P=0.64)$, 過去 1 年間に扔ける身長の変化率は, 小学 4 年生では 小学 2 年生抒よび中学 1 年生に比べて, 小学 5 年生で
は中学 1 年生に比べて有意に小さかった（Fig. 3A）。体 重の変化率は, 中学 1 年生が他の学年よりも有意に大 きかった (Fig. 3B)，成長期の体格指数であるローレル 指数に扔いては, 学年の主効果が有意であったものの $(P=0.03)$, 実験実施時 11 年前の主効果 $(P=0.38)$ と交 互作用 $(P=0.97)$ は有意水準に到達しなかった. ローレ ル指数の変化率は, 小学 2 年生と中学 1 年生との間に有 意差が認められた（Fig. 3C）。

Table 1. Straight leg raising (SLR) of hip joint flexion range of motion (RoM) before and after static stretching in each grade.

\begin{tabular}{|c|c|c|c|c|c|}
\hline \multirow{2}{*}{ School } & \multirow{2}{*}{ Grade $(n)$} & \multirow{2}{*}{ PRE, ${ }^{\circ}$} & \multirow{2}{*}{$\mathrm{POST}^{\circ}$} & \multicolumn{2}{|c|}{ PRE vs. POST } \\
\hline & & & & $P$ value & Cohen's d \\
\hline \multirow[t]{5}{*}{ Elementary } & $2^{\text {nd }}(10)$ & $62.0 \pm 5.4$ & $67.5 \pm 7.5$ & $<0.01$ & $\underline{0.84}$ \\
\hline & $3^{\mathrm{rd}}(9)$ & $67.8 \pm 6.2$ & $77.8 \pm 9.7$ & $<0.01$ & $\underline{1.23}$ \\
\hline & $4^{\text {th }}(10)$ & $62.0 \pm 2.6$ & $78.0 \pm 6.7$ & $<0.01$ & $\underline{3.13}$ \\
\hline & $5^{\text {th }}(10)$ & $63.5 \pm 10.3$ & $69.5 \pm 7.6$ & $<0.01$ & 0.66 \\
\hline & $6^{\text {th }}(6)$ & $66.7 \pm 2.6$ & $70.8 \pm 4.9$ & $<0.05$ & 0.69 \\
\hline Junior High & $1^{\text {st }}(5)$ & $69.0 \pm 2.2$ & $74.0 \pm 4.2$ & $<0.05$ & 1.49 \\
\hline
\end{tabular}

Data are expressed as means \pm SD. Bold letters, statistically significant or medium effect size (ES) and italic and underlined letters, large ES.

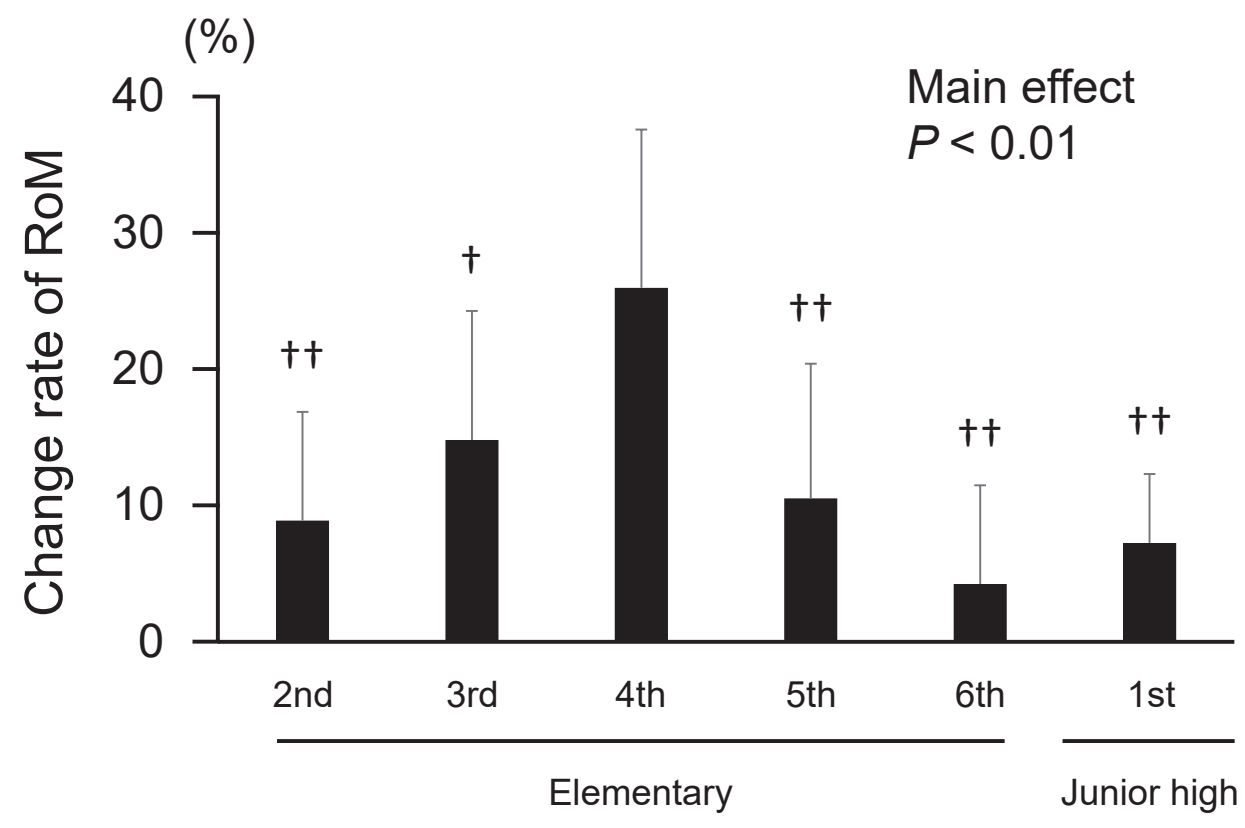

Fig. 2 Change rate of hip joint flexion range of motion (RoM) from before to after static stretching in each grade. ${ }^{\top} P<0.05$ and ${ }^{\Uparrow} P<0.01$ vs the fourth grade of elementary school. Data are expressed as means \pm SD. 
Table 2. Past and present height, body mass, and Rohrer index in each grade.

\begin{tabular}{|c|c|c|c|c|c|c|c|}
\hline \multirow{2}{*}{ School } & \multirow{2}{*}{ Grade $(n)$} & \multicolumn{2}{|c|}{ Height, $\mathrm{cm}$} & \multicolumn{2}{|c|}{ Body mass, $\mathrm{kg}$} & \multicolumn{2}{|c|}{ Rohrer index, $\mathrm{kg} / \mathrm{cm}^{3}$} \\
\hline & & 1 year ago & Present & 1 year ago & Present & 1 year ago & Present \\
\hline \multirow[t]{5}{*}{ Elementary } & $2^{\text {nd }}(10)$ & $118 \pm 4$ & $124 \pm 4^{* *++\dagger}$ & $23 \pm 2$ & $25 \pm 3^{* *++\dagger}$ & $137 \pm 12$ & $131 \pm 14^{* *++}$ \\
\hline & $3^{\text {rd }}(9)$ & $122 \pm 8$ & $128 \pm 8^{* *+\dagger}$ & $22 \pm 3$ & $25 \pm 4^{* *+\dagger}$ & $123 \pm 13$ & $119 \pm 11^{* *+}$ \\
\hline & $4^{\text {th }}(10)$ & $127 \pm 5$ & $132 \pm 6^{* *++\dagger}$ & $26 \pm 3$ & $28 \pm 4^{* *++}$ & $124 \pm 7$ & $122 \pm 11^{\dagger}$ \\
\hline & $5^{\text {th }}(10)$ & $133 \pm 5$ & $139 \pm 6^{* *+++}$ & $31 \pm 7$ & $34 \pm 7^{* *+}$ & $129 \pm 20$ & $124 \pm 17^{*+}$ \\
\hline & $6^{\text {th }}(6)$ & $137 \pm 5$ & $143 \pm 6^{* *++\dagger}$ & $31 \pm 4$ & $36 \pm 3^{* *+++}$ & $124 \pm 16$ & $123 \pm 15$ \\
\hline Junior high & $1^{\text {st }}(5)$ & $150 \pm 5$ & $159 \pm 6^{* *++\dagger}$ & $41 \pm 8$ & $49 \pm 7^{* *+++}$ & $120 \pm 18$ & $122 \pm 14$ \\
\hline
\end{tabular}

Data are expressed as means \pm SD. ${ }^{*} P<0.05$ and ${ }^{* *} P<0.01$ vs. 1 year ago and ${ }^{\dagger}$ small, ${ }^{\dagger \dagger}$ medium, and ${ }^{\dagger \dagger}$ large effect sizes. Data are expressed as means $\pm \mathrm{SD}$.

\section{考察}

対象者全体および学年毎の検討において，ストレッチ ングによる股関節屈曲 RoM の増大は有意かつ効果量が 中等度以上であった。 これらの結果から, 小学 2 中学 1 年生においてはストレッチングにより股関節 RoM は 一過性に改善すると考えられた（Table 1).しかしなが ら, その効果には学年間の差異があり, 小学 4 年生では その他の学年に比べてストレッチングによるRoMの変 化率が大きかった (Fig. 1)。 また, 小学 4 年生は過去 1 年間における身長の増大が一部の学年に比べて低值で あった（Fig. 2). 従って, 身長増進の停滞期にあったこ とが, 本研究の小学 4 年生でストレッチングによる股関 節屈曲 RoM 増大が他の学年よりも大きい理由であった 可能性が考えられる.

本研究では小学 2 中学 1 年生の男子を対象者とし た. ヒトは思春期頃にAGSを迎えること， 5 〜 歳頃 にMGSを経験することが多くの調查により確認されて いる ${ }^{15-20,22)} .9$ ～15歳 の日本人男性149名を対象にした 調査では, 13 歳前後にAGSを迎え, その $1 〜 2$ 年前に 成長速度が一時的に低下するとされている ${ }^{14)}$ 。 また, 藤 井ら ${ }^{21,22)}$ の報告でも, 日本人男子の AGS は 12〜13歳で あるとされている. 一方, 日本人男子の MGS 6 ～ 7 歳 ごろ ${ }^{22)}$ または 5 歳から AGSの $2 \sim 4$ 年前までに複数回 出現する ${ }^{21)}$ とされている. 本研究において, 小学 4 年生 ( $9 \sim 10$ 歳) で同 2 年生 $(7 \sim 8$ 歳) および中学 1 年生 $(12$ 〜13歳）に比べて過去 1 年間の身長の伸びが小さかっ
たことは, これらの先行研究と矛盾していない. 従って, 本研究の対象はMGSから AGSまでの年齢を概ね網羅し ていると考えられる. ストレッチングの効果が小学 4 年 生で最も高いという本研究の結果は, ストレッチングに よる柔軟性の改善は成長停滞期で高く, AGSやMGSで は低いという本研究の仮説を支持するものである.

中学校サッカー部員における研究 ${ }^{27)}$ では, 最高身長成 長速度 (peak height velocity: PHV) が出現する前の者 に比べて出現後の者ではSLRによるRoM 等の成績が低 值であった。サッカーの練習では準備運動として静的ま たは動的なストレッチングを実施することが一般的であ る. 推論ではあるが, 先行研究 ${ }^{27)}$ の結果は, PHVの出現 によりストレッチングの効果が低減することを示唆する のかもしれない.しかし, 発育段階とストレッチング効 果との関連性を実際に検討した研究は少ない. 体操教室 の生徒と公立小学校の生徒 (対照群) を比較した津山ら の横断的研究 ${ }^{28)}$ では, 体操教室群における長座体前屈の 成績は $9 ， 11 ， 12$ 歳では優れていたが，8および10歳で は対照群と同等であった。ただし，学年により体操の継 続期間が異なる上に対照群の運動習慣は不明であり, 群 間差の有無をトレーニング効果の差異と解釈するのは性 急である。著者らの知る限り, 柔軟性に及ぼすトレーニ ング効果と年齢との関係を検討した唯一の先行研究に斎 藤らの報告 ${ }^{12}$ ) がある。この研究では, 体操教室（週 2 回, 2 力月間）の前後に立位体前屈および体後屈を行ったと ころ, 前者は 4, 5, 7，9，10歳児で, 後者は 4 歳 児だけで測定值の有意な増大が認められたことから，4 
A

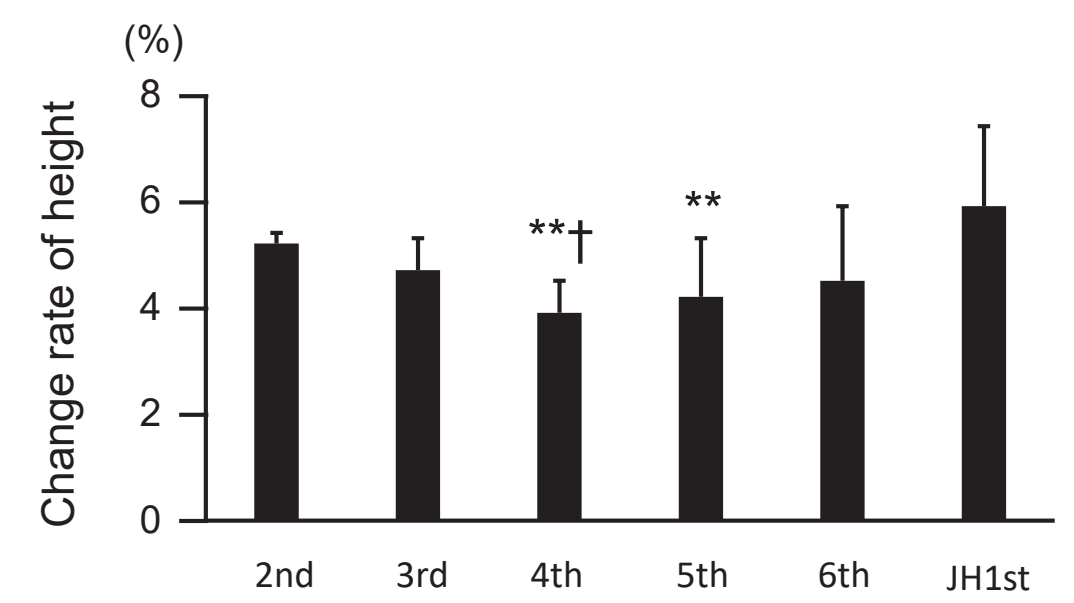

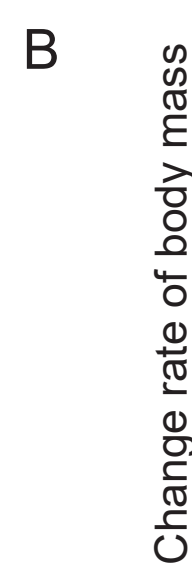

$(\%)$

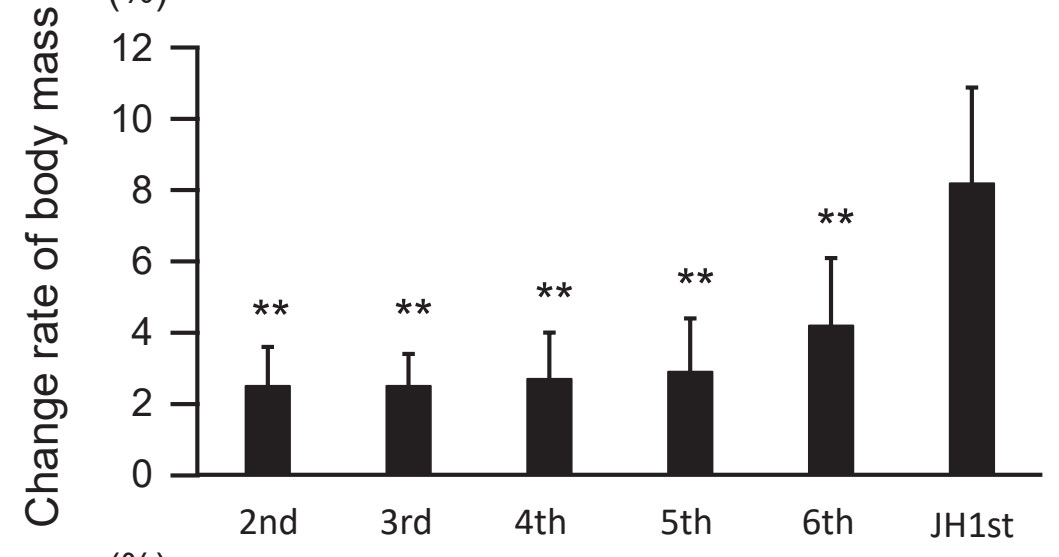

C

$(\%)$

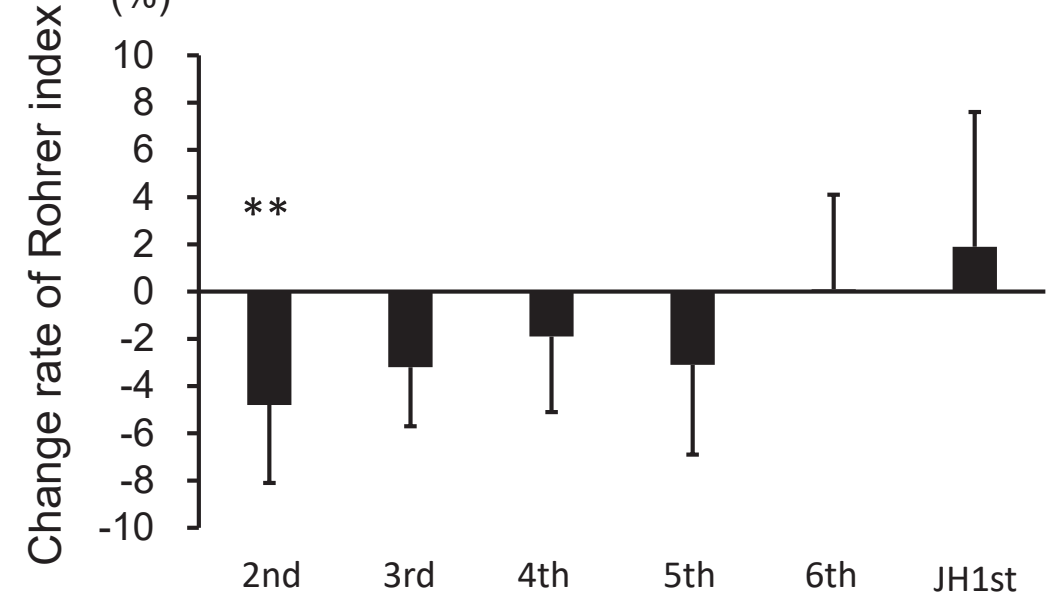

Fig. 3 Change rate of height (A), body mass (B), and Rohrer index (C) during the past year in each grade. ${ }^{* *} P<0.01$ vs. the first grade of junior high school and ${ }^{\dagger} P<0.05$ vs. the second grade of elementary school. JH, junior high school. Data are expressed as means \pm SD.

歳児で柔軟性のトレーニング効果が高いと指摘されてい る。しかし，群により男女比が異なる $(0: 5 \sim 6: 1)$, AGS に該当する対象者が含まれていない, 体後屈改善の余地 は 4 歳児が突出して大きい等（教室参加前の平均值は 4 歳児 $[15 \mathrm{~cm}]$ より $5 \sim 10$ 歳児 $[2 \sim 7 \mathrm{~cm}]$ で満点 $[0 \mathrm{~cm}]$ に近かった)，結論を得るには必ずしも十分では ない，そこで本研究では，AGSに該当する中学 1 年生 を対象に含み, 小中学生においては学年間の差異がない
$\mathrm{SLR}^{24)}$ を用いて, 男子を対象にストレッチングの効果を 検証した。 その結果, 身長増進の停滞期にある小学 4 年 生の男子は, 小学 $2 \sim 3$ 年生拈よび小学 5 年生〜中学 1 年生に比べてストレッチングによる柔軟性の改善が大き いことが示唆された。

小学 2 年生は過去 1 年間に㧍ける身長の伸長率が小学 4 年生より大きかった。一方で, 小学 2 年生の体重増加 率は中学 1 年生を除く他学年と同等であった（Fig. 3 ). 
その結果, 小学 2 年生ではローレル指数の減少傾向が顕 著で, 同指数が上昇傾向にあった中学 1 年生との間に有 意差が認められた。 ストレッチングによる股関節屈曲 $\mathrm{RoM}$ 増大が小学 4 年生より小さかったことに対する身 長の関与は, 小学 2 年生で他学年より大きかった可能性 は考えられる。一方で, 中学 1 年生は小学 4 年生より伸 長率が大きかっただけでなく, 他の全学年より体重の増 加率が大きかった (Fig. 3). 小学 6 年生男子の股関節屈 曲 RoM および足関節背屈 RoM と体重およびBMI との 間に負の相関関係を認めた中山ら ${ }^{13)}$ は, 男子の二次性徵 にともなう骨格筋量の増大は柔軟性の制限因子になると 推測している。本研究においても, 中学 1 年生の股関節 屈曲 RoM 増大が小学 4 年生より小さかったことに骨格 筋量が関与した可能性はある。ストレッチングの効果が 小学 4 年生より小さかったことは, MGSに該当する小 学 2 年生では主に身長に, AGSに該当する中学 1 年生で は身長に加えて骨格筋量に由来する等のように, 学年に よって理由が異なるのかもしれない.

本研究で示唆されたストレッチング効果の学年差は, 学校体育や各種のスポーツ活動において, 各学年で取り 組む準備・整理運動および柔軟性トレーニングの内容, 量, 頻度等を検討するうえで重要な基礎資料に成り得る。 一方, 本研究には限界もある。まず, 本研究の対象者は 男子のみであり，得られた知見を女子に適用することは できない，この知見を学校現場および地域総合型スポー ツクラブ等で広く活用するためには, 今後, 女子を対象 にした検討が必要である。また，本研究で検討したのは 一過性のストレッチング効果である。今後, 定期的かつ 継続的なストレッチングの効果を学年間で比較したり, トレーニングの至適年齢で柔軟性を高めることが青年期 や成人後の障害発生率に及ぼす影響を検討したりするこ とも必要である.

\section{結 語}

小学 2 〜学 1 年生の男子にストレッチングを実施さ せ，その前後でSLRにより股関節屈曲RoMを評価した ところ，全学年でSLRによるRoMは向上し，特に小学 4 年生でその向上が大きかった。過去 1 年間の身長増大 は小学 4 年生で他の学年に比べて小さかった。身長増大 が停滞する学年で, ストレッチングによる一過性の柔軟 性増大が大きくなるのかもしれない.

\section{利益相反自己申告}

本研究に利益相反として申告すべき内容は含まない.

\section{著者貢献}

著者 SA と著者 OG-Tは, 研究デザインとプロトコルを考 案し, データ収集および一過性運動のストレッチング指導
を行った，著者SA と著者Z-MAは，データの分析，解釈， 本論文執筆を担当した。著者 $\mathrm{OT}$-Tは，研究デザインとプ ロトコル考案時にアドバイザーとなり，また，本論文の推 敲を担当した，著者全員が本論文の投稿を承認した。

\section{引用文献，参考図書}

1）帖佐悦男：学童期運動器検診とその動向, Jpn J Rehabil Med 55: 9-13, 2018.

2）栗原 靖, 烏野 大, 松田雅弘, 大杉紘徳, 森下勝行, 横井悠 加, 河辺信秀, 桑江 豊, 藤川提碁 : 大学女子ソフトボー 儿選手の関節可動域と肩痛との関連性, 日臨スポーツ医 会誌, 27:425-430, 2019.

3）滝澤恵美, 小林育斗, 川村紗世, 岩井浩一：児童における しゃがみ動作の可不可および関節間協調性に関連する 要因, 理学療法学, 46: 225-232, 2019.

4）丹羽涼子, 小西裕之, 清水紀人, 大島義晴, 畑山祐子：脚 開角度と柔軟性との関係について; 片足踏み切り前後開 脚ジャンプの場合, 仙台大学紀要, 36: 32-39, 2005.

5) Morrin N, Redding E. Acute effects of warm-up stretch protocols on balance, vertical jump height, and range of motion in dancers. J Dance Med Sci 17: 3440, 2013.

6) Medeiros DM, Cini A, Sbruzzi G, Lima CS. Influence of static stretching on hamstring flexibility in healthy young adults: Systematic review and meta-analysis. Physiother Theory Pract 32: 438-445, 2016.

7) Santonja Medina FM, Sainz De Baranda Andújar P, Rodríguez García PL, López Miñarro PA, Canteras Jordana M. Effects of frequency of static stretching on straight-leg raise in elementary school children. $J$ Sports Med Phys Fitness 47: 304-308, 2007.

8) Donti I, Papia K, Toubekis A, Donti A, Sands WA, Bogdanis GC. Flexibility training in preadolescent female athletes: Acute and long-term effects of intermittent and continuous static stretching. J Sports Sci 36: 1453-1460, 2018.

9）大澤清二 : 体力トレーニング開始の最適年齢を求めて, 体育の科学, 63: 181-186, 2013.

10）マイケル J. オルター（山本利春監訳）, 子供と柔軟性の 発達, 柔軟性の科学, 大修館書店, 東京, 28-29, 173-176, 2010 .

11) Sermeev BV. Development of mobility in the hip joint in sportsmen. Yessis Rev 2: 16-17, 1966.

12）斎藤 卓, 松元正竹, 井上尚武, 児玉光雄, 北川淳一, 萩 裕 美子, 金高宏文, 北村尚浩, 永嶺康雄 : 幼児 - 児童を対 象とした体操教室における運動能力・柔軟性のトレー ニング効果：NIFSスポーツクラブ「楽しい体操教室」 の実践を通して, 鹿屋体育大学学術研究紀要, 35: 61-66, 2007.

13）中山 朗, 長住達樹 : 成長期児童の下肢柔軟性と体格と の関係, 理学療法科学, 26: 19-22, 2011.

14）福永裕子, 西薗秀嗣：成長期の縦断的身長成長速度から みた下肢スポーツ障害の発症要因に関する研究, 体力科 学, 59: 521-528, 2010.

15) Count EW. Growth patterns of the human physique an approach to kinetic anthropometry. Hum Biol 15: 1-32, 
1943.

16) Tanner JM. The morphological level of personality. Proc R Soc Med 40: 301-303, 1947.

17) Molinari L, Largo RH, Prader A. Analysis of the growth spurt at age seven (mid-growth spurt). HelV Paediatr Acta 35: 325-334, 1980.

18) Gasser T, Muller HG, Kohler W, Prader A, Largo R, Molinari L. An analysis of the midgrowth and adolescent spurts of height on acceleration. Ann Hum Biol 12: 129-148, 1985.

19) Matsuura Y, Kim M. Analysis of physical growth by fitting the polynomial to the longitudinal growth distance data of individual age 6 to 17. Research Monograph issued by Growth and Development Research Institute of Health and Sports Sciences, University of Tsukuba, 1-153, 1991.

20) Matsuura Y, Kim M. Analysis of physical growth by fitting the polynomial to its growth distance data --Girl's stature and body weight--. J Korean Public Health Assoc 17: 130-148, 1991.

21）藤井勝紀：身体発育現象としての mid-growth spurtの
検証, 体育学研究, 47: 347-359, 2002.

22）藤井勝紀, 䅖丸武臣, 花井忠征, 酒井俊郎：幼児の体格· 運動能力の発育・発達に扮ける年次変化に関する検 証 一身体成熟度から見たアプローチー, 体力科学, 55: 489-502, 2006.

23）中川 梓, 下永田修二：月経周期に伴う柔軟性の変化に 関する研究, 千葉体育学研究, 40: 29-30, 2018.

24）宿谷あゆみ, 小粥智浩, 膳法亜沙子, 大梘 毅：小中学生 の柔軟性は発育発達に伴い増大するか？体育の科学, 67: 133-138, 2017.

25) Roberts JM, Wilson K. Effect of stretching duration on active and passive range of motion in the lower extremity. Br J Sports Med 33: 259-263, 1999.

26) Cohen J. A power primer. Psychol Bull 112: 155-159, 1992.

27）中澤理恵, 坂本雅昭, 草間洋一：中学生サッカー選手に おける身長成長速度曲線と下肢筋柔軟性との関係, 理学 療法科学, 22: 119-123, 2007.

28）津山薰, 南 明恵美, 松阪裕実, 金 相勲, 清田 寛 : 定期的 な体操が女子児童の筋力, 平衡感覚, 柔軟性に及ぼす影 響, 日本体育大学紀要, 38: 9-16, 2008. 